\title{
Traumatic bone cyst of anterior mandible: A surgical approach
}

\author{
Karthik KP ${ }^{1}$, Balamurugan $\mathrm{R}^{1 *}$ and SahanaPushpa $\mathrm{T}^{2}$ \\ ${ }^{1}$ Oral and Maxillofacial Surgeon, India \\ ${ }^{2} \mathrm{PG}$ Trainee, Oral and Maxillofacial Pathologist, India
}

\begin{abstract}
This case report presents a 23 year old male patient who reported with pain in his anterior mandible since a week. History revealed an incidence of trauma on his chin when he was young for which he did not undergo any treatment. On examination buccal cortical expansion was clinically evident and tenderness was elicited on percussing over the lower anterior teeth. Aspiration was negative initially while, it showed serous blood the second time. Radiograph featured a unilocular radiolucency extending from left mandibular first premolar to right mandibular first molar with evidence of inter-radicular scalloping. With all these clinical and radiographic features we could arrive at a provisional diagnosis of traumatic bone cyst. A complete surgical excision followed by curettage of the cystic cavity was performed. The excised specimen was sent for histopathological evaluation. Histology showed presence of dense connective tissue, chronic inflammatory cell infiltrate and a normal bone with no epithelial lining.
\end{abstract}

\section{Introduction}

Traumatic bone cyst (TBC) is a rare, asymptomatic, intraosseous lesion considered to be a pseudocyst of jaws and long bones [1]. It is otherwise regarded as solitary bone cyst, hemorrhagic bone cyst, simple bone cyst, extravasation cyst or progressive bone cyst [2]. A lesion with such a multitude representation lacks accurate understanding of its etiopathogenesis. This lesion has predilection for young males in second decade of life with long bones (90-95\%) being the most frequently affected site followed by symphysis and body of mandible (75\%), humerus (65\%), femur (25\%) and a rare involvement of maxilla [3] and condyle (1\%) [4]. TBC is asymptomatic hence it is discovered through routine radiographs as an accidental finding. Though expansion of cortical plates are rarely noticed [5] several instances where the lesion show expansion of buccal cortex causing extra oral and intra oral swelling leading to facial asymmetry. Radiograph features a well-defined, unilocular radiolucency with or without sclerotic margins extending between the roots of the tooth in the affected region, providing a characteristic scalloping feature. Histological findings reveal a fibrous connective tissue with chronic inflammatory cell infiltrate without epithelial lining. The gold standard treatment for such a lesion includes surgical excision followed by curettage of cystic cavity. Surgical exploration induces bleeding which forms a blood clot within the cavity, which in turn leads to resolution and regeneration of new bone $[2,3]$.

\section{Case presentation}

A 23 year-old male patient reported to the Department of Oral and Maxillofacial Surgery with a chief complaint of pain in the anterior tooth region of mandible since 7 days which was sudden and intermittent in nature. He had a history of trauma on his chin when he was young and he was not treated for the same. Extraorally, there was no significant facial asymmetry. Intraoral examination showed obliteration of vestibule in mandibular anterior region and tenderness was elicited on percussion. Vitality test revealed that all the associated teeth were vital (Figure 1).

Orthopantamograph (Figure 2) showed presence of a unilocular radiolucent lesion extending from the mandibular left first premolar to the mandibular right first molar. Superoinferiorly it extends from the root apices of the tooth to $2 \mathrm{~mm}$ above the inferior alveolar nerve. There was an empty aspiration initially and serous blood was obtained during second aspiration performed in different angulations. On the basis

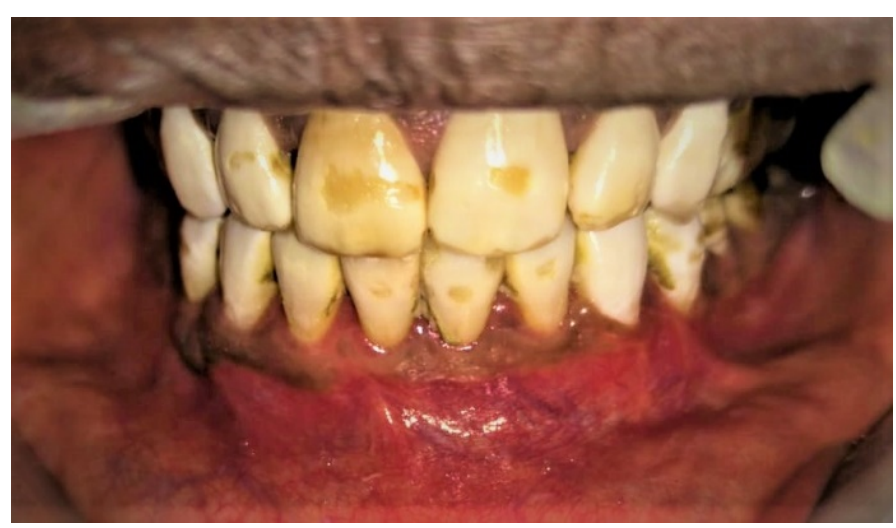

Figure 1. Intra oral view showing obliteration of buccal vestibule

${ }^{*}$ Correspondence to: Balamurugan R, MDS, Oral and Maxillofacial Surgeon, RYA COSMO Foundation Hospital, India, E-mail: bala100192@gmail.com

Key words: anterior mandible, unilocular radiolucency, interdental scalloping, traumatic bone cyst

Received: June 12, 2019; Accepted: June 28, 2019; Published: July 03, 2019 
of the clinical and radiological features the lesion was provisionally diagnosed as traumatic bone cyst. Surgical excision of the lesion along with curettage of cystic cavity followed by primary closure was planned as treatment.

\section{Surgical procedure}

Under Nasotracheal intubation general anesthesia was administered. Standard painting and draping was done. Intra oral betadine irrigation was done and local anesthesia was infiltrated along the vestibule of mandible (Figure 3). Crevicular incision was placed with vertical releasing incision in the molar region bilaterally. Mucoperiosteal flap was reflected to expose the underlying bone. Thinned buccal cortex was removed to expose the underlying lesion. The cyst was completely excised from the cavity and peripheral ostectomy was performed (Figure 4), which was then curetted and washed with betadine. Later the cavity was induced with blood to undergo spontaneous resolution and formation of new bone (Figure 5). The flaps were sutured with 3-0 vicryl. Patient was extubated and shifted to ICU uneventfully. The obtained specimen from the surgical site was sent for histopathological evaluation. Histology featured a thin inflamed connective tissue lining the cavity with chronic inflammatory cells and fibroblasts. It also had few bony fragments and osteocytes (Figure 6).

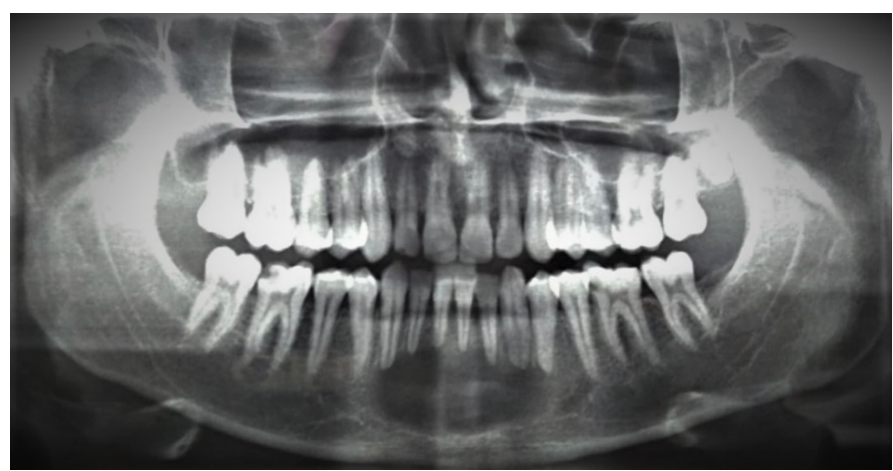

Figure 2. Orthopantamograph showing unilocular radiolucency extending from mandibular left first premolar to mandibular right first molar with superoinferior extension from root apices of the tooth to $2 \mathrm{~mm}$ above the inferior alveolar nerve

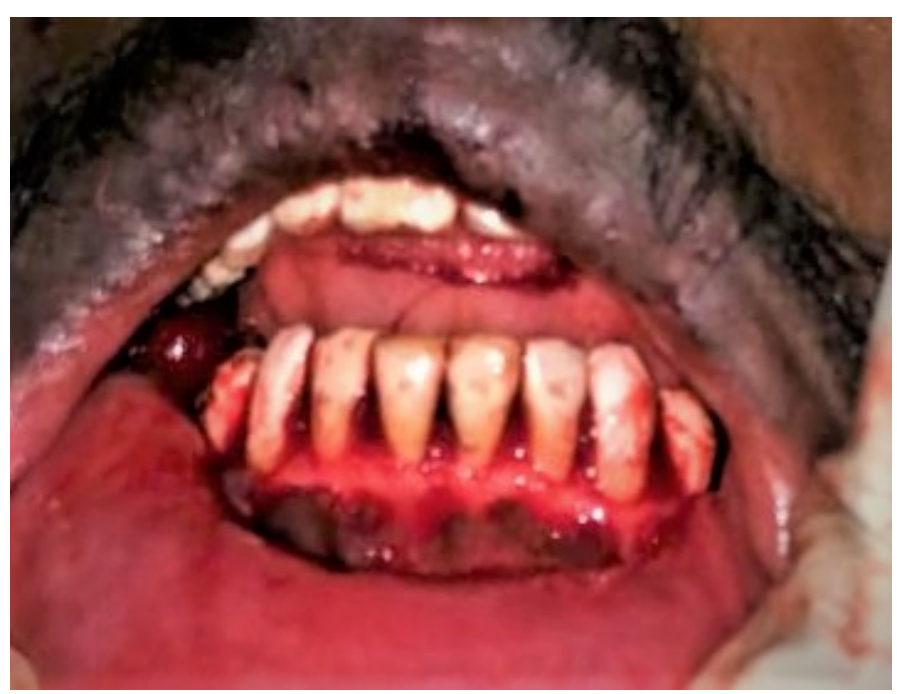

Figure 3. Clinical extent of lesion in the anterior mandible

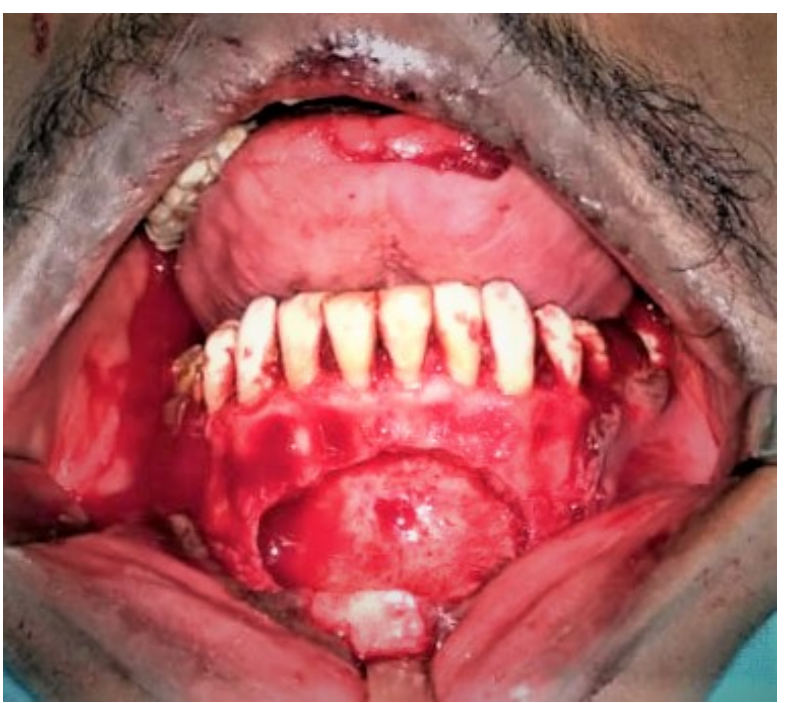

Figure 4. Elevation of mucoperiosteal flap, enucleation of cyst followed by periphera ostectomy

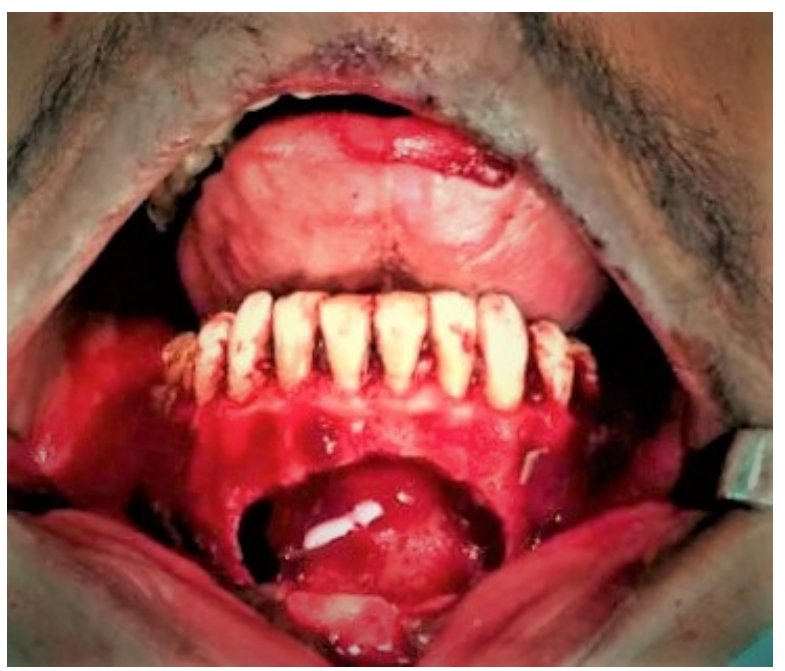

Figure 5. Bleeding induced within the cystic cavity to undergo spontaneous resolution and regeneration of new bone

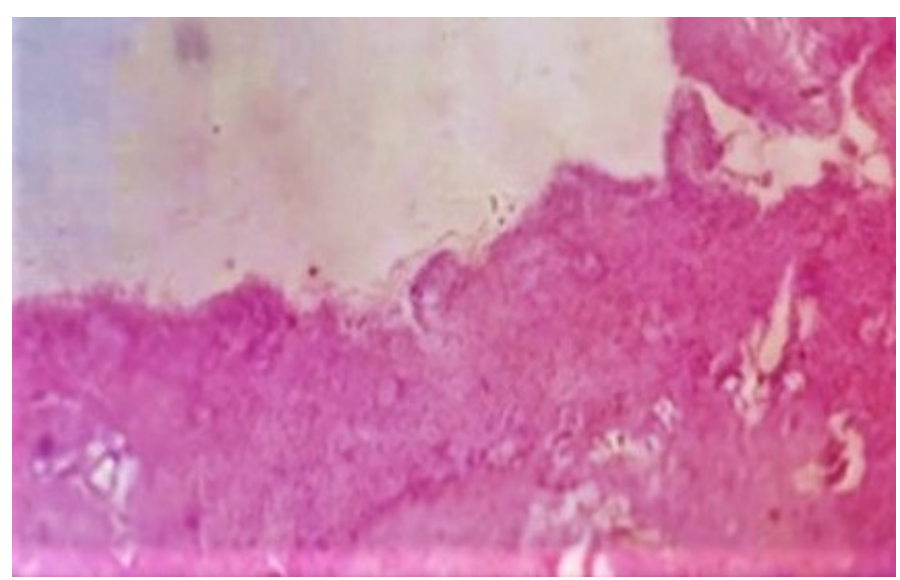

Figure 6. Histopathologically, a thin inflamed connective tissue lining the cavity with chronic inflammatory cells, fibroblasts, few bony fragments and osteocytes 


\section{Discussion}

Traumatic bone cyst is a rare distinct entity which was first described by Lucas and Blum in 1926 and later in 1946 it was portrayed to be a single cyst without epithelium by Rushton. The most common etiological factor is trauma [6] however the exact mode, frequency and intensity must be determined before arriving at a diagnosis. The pathogenesis of traumatic bone cyst is highly debated and still remains unclear. The most widely accepted theory was proposed by Pommer which states that trauma induces bleeding within the bony cavity, which under the enzymatic activity eventually destroys the liquefied blood clot and the surrounding bones. Blum and Thoma from their introspection revealed that a history of trauma to the jaws largely contributes in the development of TBCs. Thoma described that, initiation of trauma induce sub-periosteal bleeding causing compromise in the blood supply to the specific site leading to resorption of bone $[1,5]$.

TBC presents as asymptomatic lesion in $88.5 \%$ of the cases as per English literature [7]. But a symptom of pain may be a striking feature in $10-30 \%$ of patients. However, other symptoms include paresthesia, intraoral or extraoral swelling, fistulas and pathologic fracture are relatively uncommon $[6,8]$. Such findings are attributed to extensive involvement of lesion or its association with radicular cyst [9], ameloblastoma, odontogenic keratocyst, aneurysmal bone cyst, central giant cell granuloma, odontogenic myxoma or florid cemento osseous dysplasia $[2,10]$. In our case we experienced empty aspiration at first, while serous blood was aspirated during the second time in different angulation. Fauroux et al. [8] in his study reported with higher concentration of alkaline phosphatase on aspiration which signifies a traumatic bone associated with osseous dysplasia. Howe and Jacobs [11] revealed a fact that, cystic contents present within the cavity is purely dependent on the duration of the existing cyst. He also adds that a lesion when discovered at an early stages show aspiration of blood or serosanguineous fluid. These content starts to disintegrate with time which eventually leads to the formation of empty cavity.

TBC is generally identified as an incidental finding during radiographic evaluation which features as a homogenous unilocular radiolucency with a classic feature of interdental scalloping between the roots of the tooth in $68 \%$ of cases. Few rare cases of TBC with multilocular radiolucency was also reported by Siwach et al. [6]. MRI showed intermediate signal intensities suggestive of fluid within the cavity and dynamic MRI reveals movement of fluid from periphery into the cystic cavity [5]. Histology of traumatic bone cyst displays a connective tissue lining the cystic cavity, chronic inflammatory cell infiltrate, osteoclasts, hemorrhagic foci [7] and cholesterol crystals [6]. Yokokawa et al. [12] claims that histological evaluation could be made only in $9.52 \%$ of cases. This suggests that an empty cavity was often observed during enucleation of cyst which clearly defines the absence of epithelial lining.

The gold standard treatment modality in the management of traumatic bone cyst is to enucleate the cyst followed by curettage of the cystic cavity and inducing fresh bleeding into the surgical site $[2,5,6,10]$ with an expected healing period of 6 to 24 months [13]. Llobot et al. [3] proposed an advancement treatment protocol of TBC where he performed a continuous surgical decompression in a 15 year old child. After adequate reflection of the flap inter-radicular points were located using digital radiography to prevent any damage to the roots of involved tooth. Later trepanation was performed, reaching adequate space to drain the serohematic fluid. The bony cavity was then cannulated with the Nelaton type catheter exposing $1 \mathrm{~cm}$ of the catheter to achieve continuous drainage as well as to avoid risk of obstruction which was secured with 3-0 silk sutures. This offered various advantages of being non-toxic, non-irritant and aided in achieving complete drainage. Use of bone grafts or synthetic materials such as hydroxyapatite crystals, bioglass [14] gel foam, platelet rich plasma, autologous blood injections and bone chips after enucleation of cyst also shown to have favourable outcomes [5].

Recurrence of traumatic bone cyst are rare. Suei et al. [15] in his study recorded a recurrence rate of $26 \%$ with single cyst cavity in 132 cases. However high recurrence rates of 71 to $75 \%$ are also encountered in multiple cyst cavities cases within 3 months of surgery $[7,15]$. Complications include neurological deficits and pathological fractures in cases where extensive surgical interventions are required [5].

\section{Conclusion}

Traumatic bone cyst, addressed by a variety of names create a situation of conflicts in arriving at a definitive diagnosis. Trauma may be a key factor in the development of TBCs however its etiopathogenesis is not yet convincingly sufficient. Hence correlation of presented history, clinical findings and radiographic evaluation is essential in arriving at a confirmatory diagnosis and thereafter to plan an appropriate treatment protocols.

\section{References}

1. Battisti MPL, Soares MQS, Rubira CMF, Bullen IRFR, Lauris JRP, et al. (2018) Assessment of spontaneous resolution of idiopathic bone cavity. J Appl Oral Sci 26 : e20170288. [Crossref]

2. Madan R, Sharma S, Balani A, Rathod P, Hathgain U, et al. (2018) Traumatic bone cyst of the mandible: A case report and brief review of the literature. Int J Oral Care Res 6: 117-120.

3. Llobet LB, Soler EL, Mashala EI, Rius JM (2019) Continuous surgical decompression for solitary bone cyst of the jaw in a teenage patient. Case Reports in Dentistry 9137507: 6

4. Kim HK, Lim JH, Jeon KJ, Huh JK (2016) Bony window approach for a traumatic bone cyst on the mandibular condyle: a case report with long-term follow-up. J Korean Assoc Oral Maxillofac Surg 42: 209-214. [Crossref]

5. Panneerselvam E, Panneerselvam K, Chanrashekar SS (2014) Solitary bone cysts-A rare occurrence with bilaterally symmetrical presentation. J Oral Maxillofac Pathol 18: 481 .

6. Siwach P, Bhalchim SG, Thakur A (2018) Multilocular radiolucent lesion in anterior mandible. International Journal of Medical and Health Research 4: 144-47.

7. Martins-Filho PR, Santos Tde S, Araújo VL, Santos JS, Andrade ES, et al. (2012) Traumatic bone cyst of the mandible: a review of 26 cases. Braz J Otorhinolaryngol 78: 16-21. [Crossref]

8. Fauroux MA, Champfleur SM, Torres JH (2014) Simple bone cyst associated with florid osseous dysplsia: 2 case reports. Med Buccale Chir Buccale 20: 41-45.

9. Dincer O, Kose TE, Cankaya AB, Aybar B (2012) Traumatic bone cyst mimicking radicular cyst. BMJ Case Rep 2012. [Crossref]

10. Zemmouri Y, Chbicheb S, Wady WEI (2018) Surgical management of solitary mandibular bone cyst: A case report. Acta Scientific Dental Sciences 2: 12-15.

11. Xanthinaki AA, Konstantinous, Choupis Starvos P (2006) Traumatic bone cyst of the mandible of possible iatrogenic origin: a case report and brief review of the literature. Head and Face Medicine 2: 40.

12. Yokokawa M, Tanaka S, Ono M, Sakamoto S, Kato M, et al. (2011) Traumatic bone cyst of the mandible diagnosed using contrast- enhanced magnetic resonance imaging. Int J Oral Med Sci 10: 31-36.

13. Dias SL, Silva LF, Vieira TSLS, Paraguass $\tilde{A}^{\circ}$ GM, Lambert PLR, et al. (2012) Simple bone cyst: A case report and review of the literature. J Health Sci Inst 30: 295-8. 
14. Surej Kumar LK, Kurien N, Thaha KA (2015) Traumatic bone cyst of mandible. $J$ Maxillofac Oral Surg 14: 466-469. [Crossref]
15. Noffke CE, Raubenheimer EJ, MacDonald D (2012) Fibroosseous disease: Harmonizing terminology with biology. Oral Surg Oral Med Oral Pathol Oral Radiol 114: 388-92.

Copyright: (C2019 Karthik KP. This is an open-access article distributed under the terms of the Creative Commons Attribution License, which permits unrestricted use, distribution, and reproduction in any medium, provided the original author and source are credited. 